\title{
Multi Response Optimization of Submerged Arc Welding Using Taguchi Fuzzy Logic Based on Utility Theory
}

\author{
Zuhair Issa Ahmed AlDawood ${ }^{1}$, Ali Malik Saadoon ${ }^{2}$ \\ ${ }^{1}$ AlBani University College, Baghdad, Iraq \\ ${ }^{2}$ University of Baghdad, Engineering Affairs Department, Baghdad 17001, Iraq
}

\begin{abstract}
The submerged-arc welding (SAW) process is an essential metal-joining process used in industry. SAW is applied for pressure vessels, heat exchangers, shipbuilding, line piping, and petroleum industries. The present work investigated the optimization of SAW parameters of 10-mm thick SA516 grade 70 steel to achieve the desired mechanical properties of the weld. Three SAW process parameters were investigated, each at three different levels: welding current (300, 350, and $400 \mathrm{~A})$; arc voltage (32, 36, and $40 \mathrm{~V})$; and welding speed $(26,28$, and $30 \mathrm{~cm} / \mathrm{min})$. Sample plates measuring $500 \times 500 \times 10 \mathrm{~mm}$ were used to test the parameters. The weld quality and properties were evaluated using the following response parameters: Ultimate Tensile Strength (UTS), Ultimate Bending Force $(\mathrm{UBF}), \mathrm{HB}$ Macrohardness (HB), and the Charpy Impact Test (CIT). Utility-based fuzzy logic was used to convert the complex multiple objectives into a single utility, Multi Performance Characteristic Index (MPCI). The MPCI response values were measured using the fuzzy inference system, Mamdani type. The results revealed that the optimal SAW parameters are welding current 400 A, arc voltage 40 $V$, and welding speed $30 \mathrm{~cm} / \mathrm{min}$. All process parameters had significant effects based on analysis of variance $(A N O V A)(P<0.05$ for all). Welding current had a major effect (37.03\%) on the response parameters, followed by welding speed (32.9\%) and arc voltage (30.07\%).
\end{abstract}

Keywords: ANOVA, S/N ratio, Taguchi, Utility Theory, Fuzzy Logic, Parameter Optimization

\section{Introduction}

SAW is type of fusion welding (non-pressure welding), it is accomplished by heating that result from the arc between continuously electrode (filler metal) and workpiece. First used of SAW was in Russia in 1935 by the E. O. Paton Electric Welding Institute [1]. SAW is first automated AW processes. It uses a continuous, consumable electrode bare wire, with granular flux used to cover and shield the weld. The electrode bare wire is feed from a coil into the weld pool automatically. The flux is supplied from hoper were moves into the weld pool slightly upside down. The spatter, sparks and radiation that are so hazardous in other AW were prevented by the flux which makes welding process completely submerged. The impurities are removed by flux that is close to the arc, which is mixed with molten metal in weld which forms a glasslike slag, it solidifying on top of weld. It's chipped away after welding. The protection and thermal insulation of weld area were provided by the unfused flux layer and slag. Resulting in relatively slow cooling and a high quality of weld, noted for toughness and ductility. The remaining unfused flux after welding can be recovered and reused [2]. The parts welded by SAW must always be in a horizontal orientation because of the gravity feed of the granular flux, and a backup plate is often required beneath the joint during the welding operation. Low-carbon, lowalloy, and stainless steel can be readily welded by SAW. The main applications of SAW are pressure vessels, power plant, longitudinal and circumferential seams pipes and welded components for heavy machinery, tanks, heavy structural steelwork, offshore structures and shipbuilding [3, 4]. Various optimization methods have emerged to define the desired output parameters through developing mathematical models to establish the relationship between the process parameters and response parameters. S. Ajay et al. (2009) applied Taguchi L25 (OA) based VIKOR method in order to solve multi-response optimization problem through SAW. Four welding parameters such as arc voltage, wire feed, welding speed and electrode stick-out had been optimized with four response parameters such as bead width, depth of penetration, weld reinforcement and \% dilution. The $\mathrm{S} / \mathrm{N}$ ratio of VIKOR index has been calculated to find optimal parameters level [5]. J. Deb Baram et al. (2012) applied Taguchi based on utility theory. Taguchi L16 OA design matrix was selected. It is efficient to investigate the optimal parameters setting. Three process parameters which are electrode stick-out, wire feed and welding speed have been considered as input parameters. Response parameters such as toughness, hardness and tensile strength have been considered as output parameters [6]. G. Purohit and Digamber (2012) adopted Taguchi based grey relational analysis optimization technique to achieve acceptable weld bead geometry and HAZ weld by SAW on mild steel. Design of experimental employed using Taguchi's L25 OA to optimize process parameters such as welding speed, wire feed speed, nozzle-to-plate distance and arc voltage. The response parameters which are weld reinforcement, bead width and depth of penetration. ANOVA employed to study the significance of process parameters [7]. S. Alam and M. Khan (2012) investigated effect of SAW process parameters which are (arc voltage, welding current wire feed speed, welding speed and distance of nozzle-to-plate) on weld bead width of plate welds of low carbon steel specimen. Experimental were design using two levels full factorial. Mathematical model developed using multiple regression analysis to predict weld width. ANOVA were used to

\section{Volume 6 Issue 12, December 2017}




\section{International Journal of Science and Research (IJSR) \\ ISSN (Online): 2319-7064}

Index Copernicus Value (2016): 79.57 | Impact Factor (2015): 6.391

checked significance of the process parameters [8]. P. Bamankar and S. M. Sawant (2013) studied the effect of SAW parameters on penetration and width of bead of mild steel plates. Taguchi design (L9) OA, the input parameters used are arc voltage, welding speed and welding current. S/N ratio used for optimization the welding parameter. ANOVA used to indicates the significant values of various input parameters [9]. J. M. Satheesh and J. Edwin Raja Dhas (2014) applied desirability function approach combined with fuzzy logic analysis to optimize the multiple quality response (bead reinforcement, bead width, bead penetration and dilution) of SAW, process parameters (welding current, arc voltage, welding speed and electrode stick-out) of SA 516 grade 70 carbon steels. Experiments were design using Taguchi's L27 OA with varying welding process parameters. From analysis of Taguchi's using $\mathrm{S} / \mathrm{N}$ ratio the results are carried to optimal process parameters it is show that electrode stick-out and welding current are major parameter which effect the weld quality of SA516 Gr. 70 steel [10]. P. Deshmukh and S.N. Teli (2014) applied Taguchi L9 OA experimental design to studied the effected of SAW process parameters which are welding speed, welding current, arc voltage, and electrode stick-out with three levels for each on the penetration depth which is response parameter. ANOVA used to indicates the significant values of various input parameters. Taguchi analysis using $\mathrm{S} / \mathrm{N}$ ratio was used to find the optimal SAW parameters. The relationship between the response and welding parameters was determined by using multiple regression analysis [11]. Zuhair Issa and Ali Malik (2015) adopted design of experimental using Taguchi method L9 (OA) of SAW for ASTM SA516 grade 70. Three SAW parameters was selected (welding current, arc voltage and welding speed) and three levels for each, UTS and HB macrohardness selected as response parameters. $\mathrm{S} / \mathrm{N}$ ratio computed to calculate the optimal process parameters. Percentage contributions of each parameter are validated by using ANOVA technique [12].

\section{Utility Theory Based Fuzzy Logic}

\subsection{Utility Theory}

The usefulness of process/ product in relation to expectation of users. Overall usefulness of the process or product represented by unified index termed as "overall utility", it's sum of individual utility of various quality parameters of the process or product. The methodology for utility approach is to convert the estimate value of each quality parameters into a common index $[6,13]$. If $\mathrm{Xy}$ is the effectiveness measure of a quality parameters (response) $y, p$ evaluating attributes of the outcome space, and then the joint utility function expressed as below:

$$
\mathrm{U}(\mathrm{X} 1, \mathrm{X} 2, . ., \mathrm{Xn})=\mathrm{f}(\mathrm{U} 1(\mathrm{X} 1), \mathrm{U} 2(\mathrm{X} 2), ., \mathrm{Un}(\mathrm{Xn}))
$$

Where $\mathrm{Uy}(\mathrm{Xy})$ is the utility of the yth quality characteristic. The overall utility function is the sum of individual utilities if the attributes are independent, and is given as follows:

$$
\mathrm{U}(\mathrm{X} 1, \mathrm{X} 2, \ldots, \mathrm{Xp})=\sum_{\mathrm{y}=1}^{\mathrm{p}} \mathrm{U}_{y}\left(\mathrm{x}_{\mathrm{y}}\right)_{x}
$$

The quality parameters may be assigned weights depending upon priorities or importance of parameters. The overall utility function after assigning weight to attribute can be expressed as:

$$
\mathrm{U}(\mathrm{X} 1, \mathrm{X} 2, \ldots, \mathrm{Xp})=\sum_{\mathrm{y}=1}^{\mathrm{p}} \mathrm{WyU}_{y}\left(\mathrm{x}_{\mathrm{y}}\right)_{x}
$$

\section{Where}

$\mathrm{Wy}=$ weight assign to the quality parameters $\mathrm{y}$.

Sum of all attributes weights must be equal to 1 . A preference scale for each response parameter is constructed for determining its utility value. Two arbitrary numerical values (preference number) 0 and 9 are assign to the just best value and acceptable of the response parameter. The preference number (Py) for the yth response variable can be expressed on a logarithmic scale:

$$
\mathrm{Py}=\mathrm{Ay} \times \log \left(\mathrm{Xy} / \mathrm{X}^{\prime} \mathrm{y}\right)
$$

Where $\mathrm{Xy}=$ value of yth response parameter, X'y $=$ just acceptable value of yth response parameter and $\mathrm{Ay}=$ constant for the yth response parameter. The value of Ay can be found by the condition that if Xy $=X^{\prime}$ ' $($ where X'Y is the best value or optimal for the yth response), the Py $=9$, Then,

$$
A_{y}=\frac{9}{\left.\log L_{y}^{x} / X_{y}^{y}\right)}
$$

To find the best value or optimal value $X^{\prime} y$ for the yth response the follows equation will use:

$$
\mu_{\text {opt. }}=\mu_{m}+\sum_{\mathrm{i}=1}^{\mathrm{q}}\left(\mu_{\mathrm{i}}-\mu_{\mathrm{m}}\right)
$$

The overall utility (U) can be calculated as follows:

$$
\mathrm{U}=\Sigma_{\mathrm{y}=1}^{\mathrm{p}} \mathrm{Wy}_{\mathrm{y}}
$$

Subject to the condition that $\sum_{y=1}^{p} W y=1$

Normalization using Higher-the-Better (HB) criteria was chosen using the formula

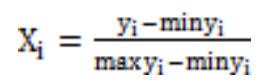

Where $\mathrm{xi}$ is the normalized value and yi observed value, min yi and max yi is smallest and largest value of yi.

\subsection{Fuzzy Logic (FL)}

The term "fuzzy" was first used in University of California by Dr. Lotfi A. Zadeh in 1965. FL is a mathematical technique for dealing with uncertainty that handles problem that cannot be solved in traditional system. Fuzzy provides a remarkably simple way to draw definite conclusions from vague, ambiguous or imprecise information. Unlike classical logic, which requires a deep understanding of a system, exact equations, and precise numeric values [14]. Unlike classic strategy of control the idea of FL is similar to human thinking. FL output results from fuzzification of output and input using related membership function (MF). The crisp 


\section{International Journal of Science and Research (IJSR) \\ ISSN (Online): 2319-7064}

Index Copernicus Value (2016): 79.57 | Impact Factor (2015): 6.391

input value will be converted to different member of MF based on its value. FL unit consist of fuzzification, MF, fuzzy rule base, inference engine and difuzzification. FLS are main successes and development of FL and fuzzy set. FLS are rules base system that implemented mapping between outputs and inputs Figure (1) show the FLS structure [15].

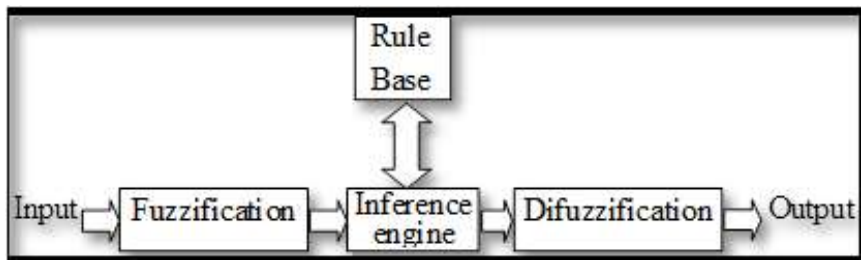

Figure 1: FLS structure

Mapping of input data to the output for FL is in part characterized by set of conditions - action rules (if-then) form. These rules can be represented in many forms the standard form are, Multi-Input Single Output (MISO) is considered in this research. MISO form of a linguistic rule is:

If $\mathrm{U} 1$ is $\mathrm{A} 1 \mathrm{U} 2$ is $\mathrm{A} 2 \mathrm{U} 3$ is $\mathrm{A} 3$ and $\mathrm{U} 4$ is $\mathrm{A} 2$ then $\mathrm{y}$ is $\mathrm{B}$ It's entire set of linguistic rule of this form that the expert specifies on how to control the system. Note that if $\mathrm{U} 1=$ "hardness" and A1 = " high" then U1 is A1 a single term in the premise of the rule, means "hardness is high" it can be easily shown that the MIMO form for a rule can be decomposed into a number of MISO rules using simple rules from logic. Is linguistically (logically) equivalent to the four rules

Rule 1 If $\mathrm{X} 1$ is $\mathrm{A} 1 \mathrm{X} 2$ is $\mathrm{B} 1 \mathrm{X} 3$ is $\mathrm{C} 1$ and $\mathrm{X} 4$ is $\mathrm{D} 1$ then $\mathrm{y}$ is $\mathrm{E} 1$

Rule 2 If $\mathrm{X} 1$ is $\mathrm{A} 2 \mathrm{X} 2$ is $\mathrm{B} 2 \mathrm{X} 3$ is $\mathrm{C} 2$ and $\mathrm{X} 4$ is $\mathrm{D} 2$ then $\mathrm{y}$ is $\mathrm{E} 2$

Rule $\mathrm{n}$ If $\mathrm{Xn}$ is $\mathrm{An} \mathrm{Xn}$ is $\mathrm{Bn} \mathrm{Xn}$ is $\mathrm{Cn}$ and $\mathrm{Xn}$ is $\mathrm{Dn}$ then $\mathrm{y}$ is $\mathrm{En}$

The inference engine defines mapping from input fuzzy output fuzzy sets. In this research Mamdani Fuzzy Inference system (FIS) was used. Centroid defuzzification method was adopted to transform the multi-response output $y_{p}$. $(y)$ refer in to a non-fuzzy value $y \circ$ which is expressed in equation 10.Center of gravity method (centroid) shown in Figure (2) [16].

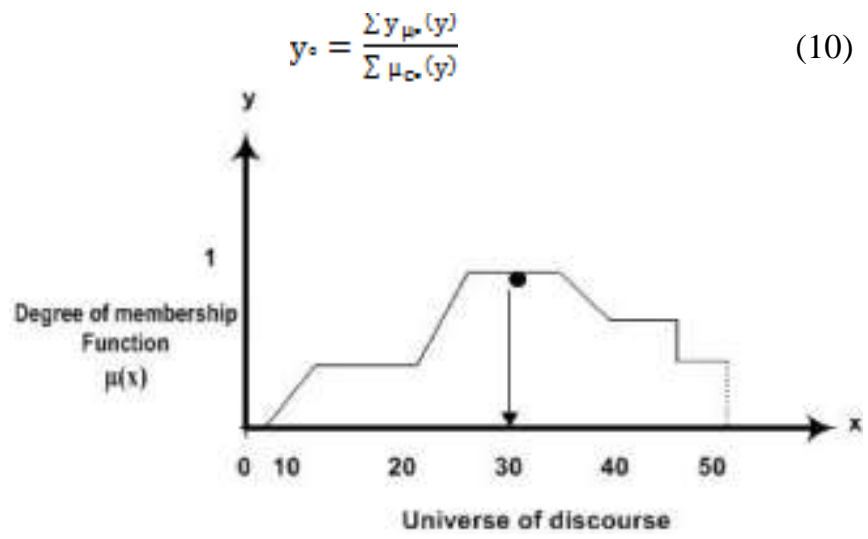

Figure 2: Center of gravity method (centroid)

\section{Proposed Methodology}

Research methodology which includes materials, welding process in SAW, experimental procedures and optimization were used in this study. All the SAW operations were carried out by certificated from Ministry of Oil /Heavy Engineering Equipment's State Company/ Iraq (HEESC). The experiments were conducted by using design of experiment. Nine principal experimental were used to evaluate the response parameters. In order to solve multi parameters optimization problem the utility theory was used. Utility theory coverts the multi parameters optimizations problems into single response optimization problems. The utility theory optimization process use following steps:

1) Design an appropriate orthogonal array to plan the experimental design and determine the level of parameters.

2) Decide which the responses parameters needed to be optimal parameters.

3) Conduct experimental design using Taguchi's L9 OA depending on number of parameters and their levels in order to give minimum experimental.

4) Record the test results of response parameters for each experiment.

5) Conduct normal probability plot in order to ensure all response at the acceptance range.

6) Calculate individual utility of each response parameter using utility theory. Each response yi is converted into an individual utility $\mathrm{Ui}$ such that $0 \leq \mathrm{Ui} \leq 1$ sum of weights is equal to one. The experimental values of response parameters are normalized in the range of $0-1$.

7) Using fuzzy inference system FIS, use process parameters as input and MPCI as output.

8) Determine the optimal parameter and its level combination based on the higher value of MPCI implies better quality.

9) Select the highest $\mathrm{S} / \mathrm{N}$ ratio for optimal parameters using Taguchi analysis.

10) Use ANOVA to indicate significant of effects parameters.

11) Determination of Optimal weld Parameters

The experiment was conducted on HEESC using ESAB welding machine with single wire, direct current, electrode positive as shown in Figure (3).

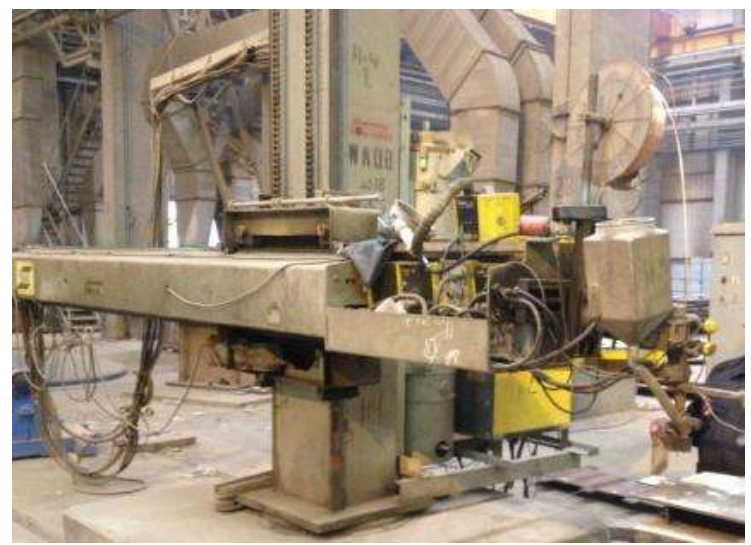

Figure 3: Photograph view of experimental setup 


\section{International Journal of Science and Research (IJSR) \\ ISSN (Online): 2319-7064 \\ Index Copernicus Value (2016): 79.57 | Impact Factor (2015): 6.391}

In the present study, three process parameters were studies, which are arc voltage (V), welding current (Amps.) and welding speed $(\mathrm{cm} / \mathrm{min}$.). Three levels for each parameter were considered according from AWS handbook. Selections of welding parameters of each level are shown in Table (1). The Input process parameters of SAW three parameters, levels and response parameters are shown in Table (2). Using Taguchi OA L9 (33) with Eight degree of freedom.

Table 1: Input process parameters of SAW three parameters and levels

\begin{tabular}{|c|c|c|c|}
\hline \multirow{2}{*}{ Parameter } & \multicolumn{3}{|c|}{ Level } \\
\cline { 2 - 4 } & 1 & 2 & 3 \\
\hline Welding Current (I) Amps. & 300 & 350 & 400 \\
\hline Arc Voltage (V) Volts & 32 & 36 & 40 \\
\hline Welding Speed (S) cm/min & 26 & 28 & 30 \\
\hline
\end{tabular}

Table 2: Taguchi design (L9) with non-normalize response

\begin{tabular}{|c|c|c|c|c|c|c|c|}
\hline \multirow{2}{*}{ Exp. } & \multicolumn{3}{|c|}{ Parameters } & \multicolumn{4}{c|}{ Response } \\
\cline { 2 - 8 } & $\begin{array}{c}\text { I } \\
\text { Amps. }\end{array}$ & $\begin{array}{c}\text { V } \\
(\mathrm{V})\end{array}$ & $\begin{array}{c}\text { S } \\
(\mathrm{cm} / \mathrm{min})\end{array}$ & $\begin{array}{c}\text { UTS } \\
(\mathrm{MPa})\end{array}$ & $\begin{array}{c}\text { UBF } \\
(\mathrm{N})\end{array}$ & $\begin{array}{c}\text { HB } \\
(\mathrm{kg} / \mathrm{mm} 2)\end{array}$ & $\begin{array}{c}\text { CIT } \\
(\mathrm{J})\end{array}$ \\
\hline A & 300 & 32 & 26 & 555 & 27194 & 177 & 54.20 \\
\hline B & 300 & 36 & 28 & 551 & 33052 & 174 & 38.03 \\
\hline C & 300 & 40 & 30 & 581 & 40374 & 177 & 31.05 \\
\hline D & 350 & 32 & 28 & 564 & 38352 & 184 & 53.51 \\
\hline E & 350 & 36 & 30 & 584 & 41599 & 184 & 104.33 \\
\hline F & 350 & 40 & 26 & 566 & 44215 & 184 & 88.57 \\
\hline G & 400 & 32 & 30 & 573 & 38226 & 189 & 35.73 \\
\hline H & 400 & 36 & 26 & 586 & 38377 & 187 & 19.48 \\
\hline I & 400 & 40 & 28 & 580 & 43704 & 198 & 23.32 \\
\hline
\end{tabular}

The base metal used for experimental work SA516 grade 70. The material was supplied as normalized condition, hot rolled. Nine plates measuring $(500 \times 400 \times 10) \mathrm{mm}$. The actual and nominal chemical composition of (ASTM A516 Grade 70) is shown in Table (3) and Table (4) respectively. The electrode used for welding was $4 \mathrm{~mm}$ diameter coppercoated welding wire which is classified by the American Welding Society (AWS) as No. EM12K the key features of this electrode are, low carbon, medium manganese, and low silicon. The chemical composition of electrode is shown in Table (5). The flux used in the welding was Lincoln F7A2EMK12, this flux is a highly active flux for handling rust helps resist porosity caused by arc blow, slows freezing slag for good weld. The chemical composition of flux is given in Table (6). The flux was baked for 2 hours at $523 \mathrm{~K}$ before use.

Table 3: Actual Chemical compositions of base metal

\begin{tabular}{|c|c|c|c|c|c|}
\hline $\mathrm{C} \%$ & $\mathrm{Si} \%$ & $\mathrm{Mn} \%$ & $\mathrm{P} \%$ & $\mathrm{~S} \%$ & $\% \mathrm{Fe}$ \\
\hline 0.15 & 0.25 & 1.35 & 0.02 & 0.01 & Bal. \\
\hline
\end{tabular}

Table 4: Nominal Chemical compositions of base metal

\begin{tabular}{|c|c|c|c|c|c|}
\hline$\% \mathrm{C}$ & $\mathrm{Si} \%$ & $\% \mathrm{Mn}$ & $\% \mathrm{P}$ & $\% \mathrm{~S}$ & $\% \mathrm{Fe}$ \\
\hline 0.27 & $0.15-0.40$ & $0.79-1.30$ & 0.035 & 0.035 & Bal. \\
\hline
\end{tabular}

Table 5: Chemical composition of AWS (EM12K) electrode

\begin{tabular}{|c|c|c|c|c|c|c|}
\hline$\% \mathrm{C}$ & $\% \mathrm{Mn}$ & $\% \mathrm{Si}$ & $\% \mathrm{~S}$ & $\% \mathrm{P}$ & $\% \mathrm{Cu}$ & $\% \mathrm{Fe}$ \\
\hline 0.12 & 1.1 & 0.23 & 0.03 & 0.03 & 0.14 & Bal. \\
\hline
\end{tabular}

Table 6: Chemical composition of the flux

\begin{tabular}{|c|c|c|c|c|c|c|c|}
\hline$\% \mathrm{SiO} 2$ & $\% \mathrm{MnO}$ & $\% \mathrm{MgO}$ & $\% \mathrm{CaF} 2$ & $\% \mathrm{Na} 2 \mathrm{O}$ & $\% \mathrm{Al} 2 \mathrm{O} 3$ & $\% \mathrm{CaO}$ & $\begin{array}{r}\% \text { metal } \\
\text { alloy }\end{array}$ \\
\hline 47 & 33 & 17 & 5 & 2 & 2 & 1 & 6 max \\
\hline
\end{tabular}

Weld samples are cut from the center of the weld specimen. The transverse face of the samples were polished using standard metallurgical procedure. The polished specimens after cleaning with alcohol are macro-etched using $2 \%$ Nital $(98 \%$ nitric acid $+2 \%$ alcohol) solution to view the geometries of the weld bead geometry.

\section{Results and Discussion}

\subsection{Determination of Optimal Weld Parameters}

Taguchi method cannot solve multi process parameters optimization problem effectively and efficiently. The basic ideas to convert the multiple response optimizations, into single response optimization problem, by utility method based on fuzzy combined with Taguchi method. It can convert from multiple responses optimization problems to a single optimization response problem. The calculated of individual utility values corresponding to each parameter are shown in Table (7).

Table 7: Individual and normalize Utility

\begin{tabular}{|c|c|c|c|c|c|c|c|c|}
\hline \multirow{2}{*}{ Exp. } & \multicolumn{4}{|c|}{ Individual Utility } & \multicolumn{3}{c|}{ Normalize Individual Utility } \\
\cline { 2 - 10 } & UUTS & UUBF & UCIT & UHB & UUTS & UUBF & UCIT & UHB \\
\hline A & 0.90 & 0.00 & 1.32 & 5.87 & 0.12 & 0.00 & 0.13 & 0.61 \\
\hline B & 0.00 & 3.14 & 0.00 & 3.84 & 0.00 & 0.40 & 0.00 & 0.40 \\
\hline C & 6.58 & 6.37 & 1.32 & 2.67 & 0.86 & 0.81 & 0.13 & 0.28 \\
\hline D & 2.89 & 5.54 & 4.33 & 5.80 & 0.38 & 0.71 & 0.43 & 0.60 \\
\hline E & 7.22 & 6.85 & 4.33 & 9.63 & 0.94 & 0.87 & 0.43 & 1.00 \\
\hline F & 3.33 & 7.83 & 4.33 & 8.69 & 0.44 & 1.00 & 0.43 & 0.90 \\
\hline G & 4.86 & 5.49 & 6.40 & 3.48 & 0.64 & 0.70 & 0.64 & 0.36 \\
\hline H & 7.64 & 5.55 & 5.58 & 0.00 & 1.00 & 0.71 & 0.56 & 0.00 \\
\hline I & 6.37 & 7.65 & 10.01 & 1.03 & 0.83 & 0.98 & 1.00 & 0.11 \\
\hline
\end{tabular}

In this study, the most popular defuzzification method is the centroid calculation, which returns the centre of area under the curve. The defuzzifier converts the fuzzy value into nonfuzzy value which is called MPCI. The MF adopted in this is triangle MF. There are three fuzzy subsets assigned in the utility value for UTS, UBF, CIT and HB: small, medium and large as shown in Figure (4). Seven fuzzy subsets are assigned in the MPCI: very very small (VVS), very small (VS), small (S), medium (M), large (L) and very Large (VL), very very Large (VVL) Figure (5). 


\section{International Journal of Science and Research (IJSR) ISSN (Online): 2319-7064}

Index Copernicus Value (2016): 79.57 | Impact Factor (2015): 6.391

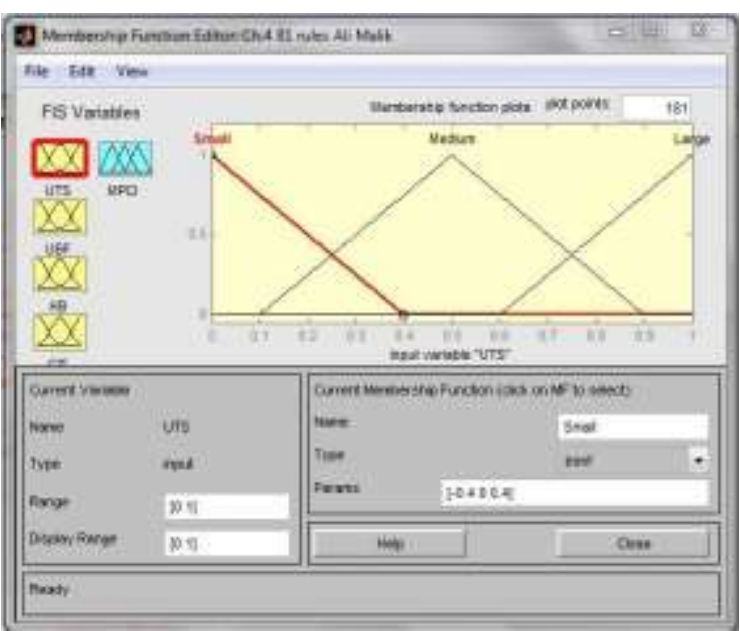

Figure 4: Membership plot for input parameters

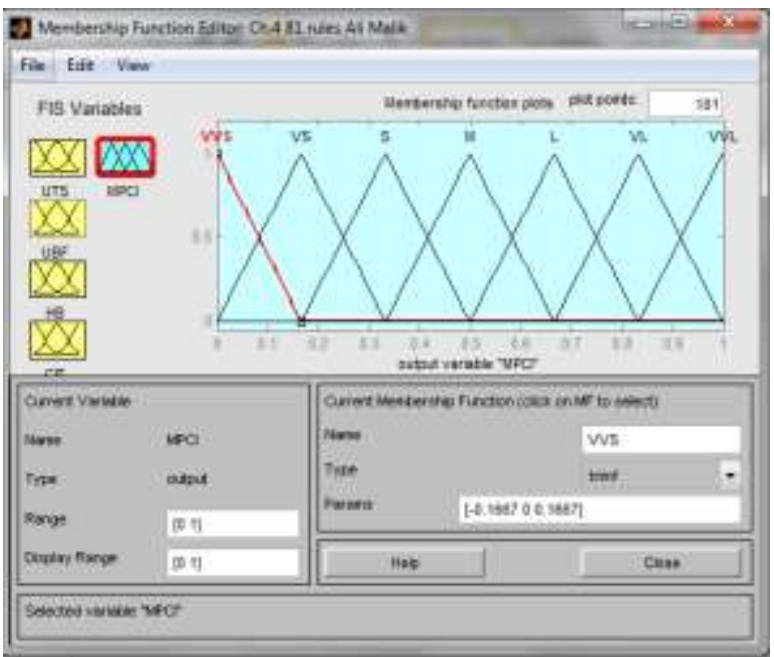

Figure 5: Membership plot for output response parameter MPCI

Various degrees of membership of the fuzzy sets are calculated based on the values of UTS, UBF, HB, CIT and MPCI. Thus, straightaway 81 fuzzy rules are derived based on the larger $\mathrm{S} / \mathrm{N}$ ratio being the better response. A fuzzy multi-response output is produced from these rules by taking the max-min inference operation. The larger the MPCI, the better is the multiple responses. Table (8) shows the experimental results for the MPCI. Thus, the multicriteria optimization problem has been transformed into a single objective optimization problem using the combination of utility theory fuzzy logic analysis. The sequence with largest MPCI indicates it is the closest to the desired values of the quality response.

Table 8: Normalize Individual Utility and MPCI

\begin{tabular}{|c|c|c|c|c|c|}
\hline \multirow{2}{*}{ Exp. } & \multicolumn{3}{|c|}{ Normalize Individual Utility } & \multirow{2}{*}{ MPCI } \\
\cline { 2 - 5 } & UUTS & UUBF & UCIT & UHB & \\
\hline A & 0.12 & 0.00 & 0.13 & 0.61 & 0.34 \\
\hline B & 0.00 & 0.40 & 0.00 & 0.40 & 0.50 \\
\hline C & 0.86 & 0.81 & 0.13 & 0.28 & 0.56 \\
\hline D & 0.38 & 0.71 & 0.43 & 0.60 & 0.50 \\
\hline E & 0.94 & 0.87 & 0.43 & 1.00 & 0.59 \\
\hline F & 0.44 & 1.00 & 0.43 & 0.90 & 0.50 \\
\hline G & 0.64 & 0.70 & 0.64 & 0.36 & 0.57 \\
\hline H & 1.00 & 0.71 & 0.56 & 0.00 & 0.56 \\
\hline I & 0.83 & 0.98 & 1.00 & 0.11 & 0.67 \\
\hline
\end{tabular}

Fuzzy analysis procedure for the optimal conditions is graphically presented in Figure (6), in which rows represent 81 rules and columns are the four inputs (UTS, UBF, HB and CIT) and one output MPCI. The location of tringle indicates the determined fuzzy sets for each inputs and output value. The reinforcement of the darkened area in each tringle corresponds to the fuzzy membership value for that fuzzy set.

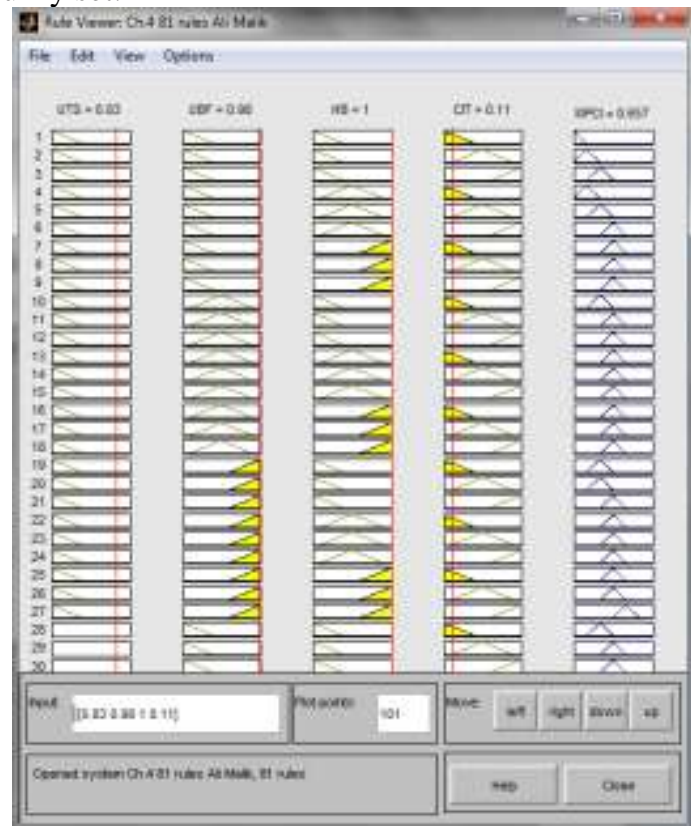

Figure 6: Fuzzy rule editors

To determine the optimal process parameters, the effect of each weld process parameter on the ratio at different levels is separated out since the experimental design is orthogonal. To obtain the effect of each process parameters on each quality response for each level, the ratios with same level of process parameter are averaged for nine experiments. The $\mathrm{S} / \mathrm{N}$ ratios for MPCI had to be calculated. Suitable S/N ratio must be chosen. In this research, the $\mathrm{S} / \mathrm{N}$ ratio was selected according to the criterion the higher is the better, in order to maximize the responses. The experimental for the welding process parameters using the L9 OA is shown in Table (9).

Table 9: Taguchi design (L9) with MPCI and S/N ratio.

\begin{tabular}{|c|c|c|c|c|c|}
\hline \multirow{2}{*}{ Exp. } & \multicolumn{3}{|c|}{ Parameters } & \multirow{2}{*}{ MPCI } & $\begin{array}{c}\text { S/N } \\
\text { Ratio }\end{array}$ \\
\cline { 2 - 4 } & I & V & S & & -9.37 \\
\hline A & 300 & 32 & 26 & 0.34 & -6.02 \\
\hline B & 300 & 36 & 28 & 0.50 & -50.04 \\
\hline C & 300 & 40 & 30 & 0.56 & -6.50 \\
\hline D & 350 & 32 & 28 & 0.50 & -6.02 \\
\hline E & 350 & 36 & 30 & 0.59 & -4.58 \\
\hline F & 350 & 40 & 26 & 0.50 & -6.02 \\
\hline G & 400 & 32 & 30 & 0.57 & -4.88 \\
\hline H & 400 & 36 & 26 & 0.56 & -5.04 \\
\hline I & 400 & 40 & 28 & 0.67 & -3.48 \\
\hline
\end{tabular}

The main effects of each parameter at three different levels on the $\mathrm{S} / \mathrm{N}$ ratio for MPCI are calculated and presented in Table (10).

\section{Volume 6 Issue 12, December 2017




\section{International Journal of Science and Research (IJSR) \\ ISSN (Online): 2319-7064}

Index Copernicus Value (2016): 79.57 | Impact Factor (2015): 6.391

Table 10: Response table for MPCI S/N ratios larger is better

\begin{tabular}{|c|c|c|c|}
\hline Level & A & B & C \\
\hline 1 & -6.809 & -6.758 & -6.809 \\
\hline 2 & -5.541 & -5.213 & -5.173 \\
\hline 3 & -4.466 & -4.845 & -4.834 \\
\hline Delta & 2.343 & 1.913 & 1.975 \\
\hline Rank & 1 & 3 & 2 \\
\hline
\end{tabular}

The main effects plots for MPCI mean and MPCI S/N ratio are shown in Figures (7).

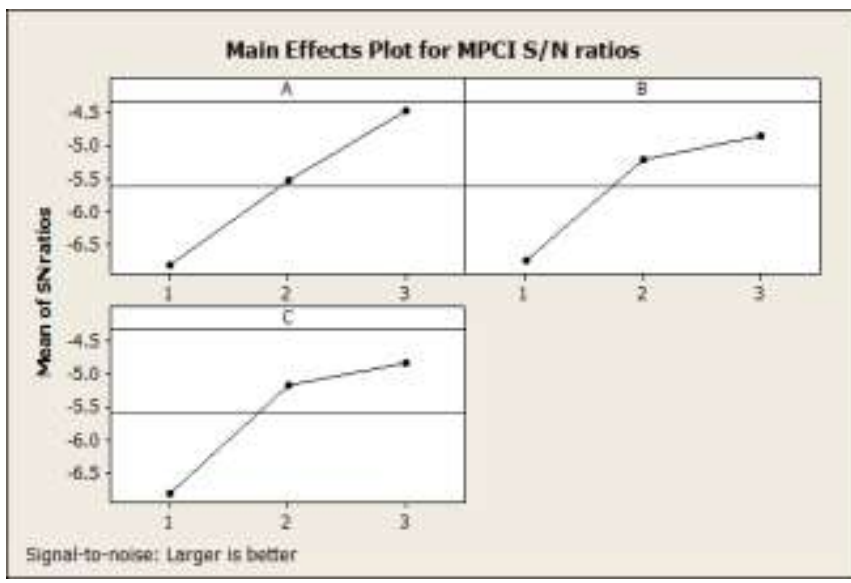

Figure 7: Main effects plot for MPCI S/N ratio

As shown Figures (7) main effects plot $\mathrm{S} / \mathrm{N}$ ratio for MPCI in this plot the $\mathrm{x}$-axis indicates the value of each process parameters at three level and $\mathrm{y}$-axis indicate the $\mathrm{S} / \mathrm{N}$ ratio value. Horizontal line indicates the mean value of the $\mathrm{S} / \mathrm{N}$. Optimal SAW parameters setting are welding current $=400$ Amps., arc voltage $=40 \mathrm{~V}$ and welding speed $=30 \mathrm{~cm} / \mathrm{min}$.

\subsection{Analysis of Variance ANOVA for MPCI}

For analyzing the significant effect of the process parameters on the response parameters, ANOVA is used. This analysis is carried out for a level of significance of 0.05 for a level of confidence of $95 \%$. ANOVA is calculated with the help of Minitab ${ }^{\circledR}$ 17. Table (11) shows output, the table indicates the significance value of various input parameters.

Table 11: Analysis of Variance ANOVA for MPCI

\begin{tabular}{|c|c|c|c|c|c|c|}
\hline Source & DF & Seq SS & Adj MS & F & P & $\begin{array}{c}\text { Contribution } \\
\%\end{array}$ \\
\hline A & 2 & 0.024715 & 0.012357 & 23.99 & 0.040 & 39.07 \\
\hline B & 2 & 0.020068 & 0.010034 & 19.48 & 0.049 & 29.25 \\
\hline C & 2 & 0.021958 & 0.010979 & 21.31 & 0.045 & 31.68 \\
\hline Error & 2 & 0.001030 & 0.000515 & & & \\
\hline Total & 8 & 0.067772 & & & & \\
\hline
\end{tabular}

From Table (11) the $\mathrm{P}$ value from ANOVA table for welding current is 0.04 , lesser than 0.05 , Hence, the, current is the significance parameter that has effect on Response parameters, also $\mathrm{F}$ value given in ANOVA table indicates the significance of current, higher $F$ value (23.99) is the significance of welding current. $\mathrm{P}$ value for arc voltage is 0.049 , lesser than 0.05 , Hence, the arc voltage is the significance parameter that has effect on Response parameters, $F$ value indicates the significance of arc voltage, higher $F$ value (19.48) is the significance of arc voltage. $\mathrm{P}$ value for welding speed is 0.045 , lesser than 0.05 , Hence, the welding speed is the significance parameter that has effect on Response parameters, $\mathrm{F}$ value indicates the significance of welding speed, higher $F$ value (21.31) is the significance of welding speed. It is found that welding parameter welding current, arc voltage and welding speed have significant effect on response parameters. Welding current more significant parameter with major influence $(39.07 \%)$ on response parameters because their corresponding $\mathrm{P}$ value is less than 0.05 . Followed by Welding speed had (31.68\%) effects on the response parameters. However, arc voltage had least (29.25\%) contribution to influence on response parameter in SAW. Figure (8) show the percentage of contribution of the significant process parameter at confidence level 95\%. The percentage error can be used to evaluate if an experiment possesses feasibility and sufficiency or not, since it is related to the uncertain or uncontrollable factors. The percentage error for contribution is $3 \%$ that indicates that the proposed method as well as the outcome in this study is proven to be highly acceptable.

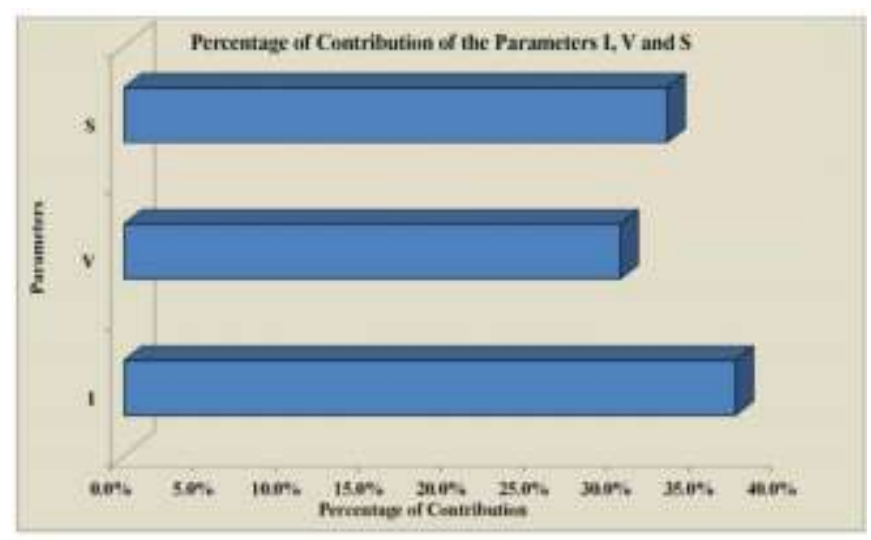

Figure 8: Percentage of contribution of the significant process parameter at confidence level $95 \%$

\section{Conclusion}

SAW test results for mechanical properties as following:

Current is the main factor that influences the depth of penetration, the depth of penetration increases with increase in current, and there is significant effect of voltage and speed on depth which in turn effects on mechanical properties.

Arc voltage and welding speed are the main factors influencing bead width. Bead width increases with increase in arc voltage, and decreases with increase in welding speed which in turn effect on mechanical properties.

Based on the $(\mathrm{S} / \mathrm{N})$ ratio results for MPCI, for the given set of parameters the optimum parameters were found at the Optimal parameters setting for larger mechanical properties is welding current $=400$ Amps., arc voltage $=40 \mathrm{~V}$, welding speed $=30 \mathrm{~cm} / \mathrm{min}$.

\section{Volume 6 Issue 12, December 2017}




\section{International Journal of Science and Research (IJSR) \\ ISSN (Online): 2319-7064}

Index Copernicus Value (2016): 79.57 | Impact Factor (2015): 6.391

From the ANOVA results for MPCI, there are a significant statically effect of process parameter conditions within the confidence level $95 \%$. The percentage of contribution of significant parameter Welding current $(39.07 \%)$, welding speed had $(31.68 \%)$ and arc voltage $(29.25 \%)$, with the percentage of error contribution is $3 \%$

From the visual examinations, no significant surface defects were observed in the welded parts.

From the photographic images and $\mathrm{X}$-ray radiographs of samples, no significant defects were observed on all the welded surfaces.

From the HB macrohardness (HB) readings, the hardness values in $\mathrm{FZ}$ are higher than those in $\mathrm{HAZ}$ and $\mathrm{BM}$, but are still higher than that of the base metal.

All tensile specimens broke in the parent metal (PM). Fracture occurring in the PM implies that the WM and the HAZ had better tensile properties than that of the PM. Since the specimens broke in the PM the yield and tensile strength values indicate that of the PM and are therefore within the same range as the un-welded parent metal.

\section{References}

[1] Parmar, R. S., 2012. Welding Processes and Technology. $3^{\text {rd }}$ Edition, Delhi, India: Khanna publishers.

[2] World Center for Material Joining Technology (TWI ltd.) 2004, Job Knowledge for Welders: Submerge Arc Welding, TWI Pub.

[3] Mikell P. Groover, 2010. Fundamentals of Modern Manufacturing: Materials, Processes, and Systems. 4th Edition, New York, USA: John Wiley and Sons,.

[4] John Norrish, "Advanced Welding Processes: Technology and Processes Control", 4th Edition, Cambridge, England: Woodhead Publishing Limited in Material, 2006.

[5] S. Ajay Biswas, Saurav Datta, Swapan Bhaumik and Gautam Majumdar "Application of Vikor based Taguchi method for Multi-Response Optimization: a Case Study in Submerged Arc Welding" Proceedings of the International Conference on Mechanical Engineering, Dhaka, Bangladesh , 26- 28 December 2009.

[6] J. Deb Barma, Joydeep Roy, S.C Saha and B. Saha Roy, "Process Parametric Optimization of Submerged Arc Welding by using Utility based Taguchi Concept" Journal of Advanced Materials Research Vols. 488489 (2012) p.p. 1194-1198.

[7] G. Purohit1 and Digamber "Optimization of bead geometry parameters of bead-on-plate weldments prepared by submerged arc welding using Taguchi Technique" International Journal of Engineering Research and Development,Vol.1, 2012, p.p.09-15.

[8] S. Alam and Ibrahim Khan, "Prediction of the Effect of Submerged Arc Welding Process Parameters on Weld Bead Width for MS 1018 Steel" International Journal of Engineering and Innovative Technology, volume 1, 2012, p.p. 205-212.

[9] P.B. Bamankar and S.M. Sawant, "Study of the Effect of Process Parameters on Depth of Penetration and Bead Width in submerged arc welding process", International Journal of Advanced Engineering Research and Studies, Vol. 2,Issue 5, 2013.

[10]M. Satheesh and J. Dhas, "Multi Objective Optimization of Weld Parameters of Boiler Steel Using Fuzzy Based Desirability Function" Journal of Engineering Science and Technology Review, Vol. 7, 2014, p.p. 29-36.

[11]P. Deshmukh and S. N. Teli, "Parametric Optimization of SAW Welding Parameters using Taguchi L9 Array" International Association of Scientific Innovation and Research, Vol. 8, 2014, p.p. 43- 47.

[12]Zuhair Issa, Ali Malik. 2015. Optimization Process Parameters of Submerged Arc Welding Using Taguchi Method. International Journal of Engineering and Advanced Technology, Vol. 5, Issue 1, p.p. 149-152.

[13] Ravinder Kataria and Jatinder Kumar, "A Comparison of the Different Multiple Response Optimization Techniques for Turning Operation of AISI O1 Tool Steel" , Journal of Engineering Research, Vol. 2, No. 4, 2014, p.p. 161-184.

[14]D. Dumitrescu, B. Lazzerini and L.C.Jain, "Fuzzy Set and their Application to clustering and Training", 1st Edition, (Library of Congress), USA: The CRC Press LLC, 2000.

[15] Usam Hameed Hanna, "Optimization of Die Geometry in Tube Sinking by Using Fuzzy Logic", M.Sc. Thesis, University of Technology, Department of Production and Metallurgy Engineering, Baghdad-Iraq, 2005.

[16] Ali Malik Saadoon, "Utility- Fuzzy Taguchi Optimization Multiple Quality Factors of Submerged Arc Welding", M.Sc. Thesis, University of Baghdad, College of Engineering, Mechanical Engineering Department, Baghdad- Iraq, 2016. 